\title{
Facile synthesis of vanadium oxide nanowires
}

\author{
Jesse Kysar $^{1} \cdot$ Praveen Kumar Sekhar $^{1}$
}

Received: 5 June 2015/Accepted: 17 October 2015/Published online: 30 October 2015

(c) The Author(s) 2015. This article is published with open access at Springerlink.com

\begin{abstract}
A simple growth process is reported for the synthesis of vanadium (II) oxide nanowires with an average width of $65 \mathrm{~nm}$ and up to $5 \mu \mathrm{m}$ in length for growth at $1000{ }^{\circ} \mathrm{C}$ for $3 \mathrm{~h}$. The vanadium (II) oxide nanowires were grown on a gold-coated silicon substrate at ambient pressure using a single heat zone furnace with $\mathrm{Ar}$ as the carrier gas. Gold was utilized as a catalyst for the growth of the nanowires. The growth temperature and heating time were varied to observe the nanowire morphology. An increase in nanowire width was observed with an increase in the heating temperature. A ninefold increase in the number density of the nanowires was observed when the heating time was changed from $30 \mathrm{~min}$ to $3 \mathrm{~h}$. This is the first time a simple growth process for producing VO nanowires at ambient pressure has been demonstrated. Such a scheme enables wider use of VO nanowires in critical applications such as energy storage, gas sensors, and optical devices.
\end{abstract}

Keywords Nanowires - Vanadium oxide - Catalyst . Thermal evaporation

Praveen Kumar Sekhar

praveen.sekhar@wsu.edu

Jesse Kysar

jesse.kysar@wsu.edu

1 School of Engineering and Computer Science, Washington State University Vancouver, 14204 NE Salmon Creek Avenue, Vancouver, WA 98686, USA

\section{Introduction}

Vanadium oxide has been applied in catalytic and electrochemical fields due to their outstanding structural flexibility combined with unique chemical and physical properties (Mai et al. 2011; Liu et al. 2005; Zhou et al. 2012; Fu et al. 2012; Dhawan et al. 2014). As an intercalation compound, vanadium oxides have attracted a lot of attention as an electrode material for electrochemical pseudocapacitor applications. In particular, nanomaterials of vanadium oxide (s) have been preferred due to high surface area to volume ratio and intriguing physical and electrical properties. Recent investigations point to the growing popularity of the nanowire morphology of vanadium oxide(s) (Hong et al. 2011; Perera et al. 2013). A variety of synthesis methods has been reported for the growth of vanadium oxide nanowires (Wang and Cao 2006). The methods include sputtering, thermal evaporation, physical vapor deposition, hydrothermal synthesis, electrospinning, and oxide-assisted growth mechanism.

Li et al. (2013) has demonstrated reactive dc magnetron sputtering as a viable technique for preparing deposits of $\mathrm{VO}_{2}$ nanorods and nanowires. According to the investigators, the nanowire formation was promoted by high substrate temperature, sufficient film thickness, proper inlet of the reactive gas, dispersed gold seeds, and pronounced substrate roughness. A novel stepwise hydrothermal methodology was developed by Horrocks et al. (2014) for preparing phase-pure $\mathrm{VO}_{2}$ nanowires based on the initial oxalic acid reduction of $\mathrm{V}_{2} \mathrm{O}_{5}$ powders to $\mathrm{V}_{3} \mathrm{O}_{7}$. Further, Mai et al. (2010) reported ultra-long hierarchical vanadium oxide nanowires with diameter of 100-200 nm and length up to several millimeters. The nanowires were synthesized using the low-cost starting materials by electrospinning combined with annealing. Single crystalline $\mathrm{VO}_{2}$ 
nanowires were grown on the surface of amorphous silica by Cheng et al. (2009). Due to the strong affinity between the vanadium oxide nanocrystals and silica surfaces, all $\mathrm{VO}_{2}$ nanowires grew along the substrate surface without the aid of any catalysts. According to the authors, the growth of $\mathrm{VO}_{2}$ nanowires was interpreted by the oxideassisted growth mechanism based on the study of the special nanowire tip structures. Cheng et al. (2012) synthesized ultra-long, ultra-dense, and free-standing $\mathrm{VO}_{2}$ micro/nanowires using a simple vapor transport method. These were achieved by enhancing the $\mathrm{VO}_{2}$ nucleation and growth rates using rough-surface quartz as the substrate and $\mathrm{V}_{2} \mathrm{O}_{5}$ powder as the evaporation source. Phase-selective growth of $\mathrm{VO}_{2}$ and $\mathrm{V}_{2} \mathrm{O}_{5}$ nanowires was realized via catalyst-free physical vapor deposition from bulk $\mathrm{VO}_{2}$ powder by Chou et al. (2009).

The current methods to synthesize vanadium oxide nanowires (NWs) are expensive, require complicated infrastructure, involve harmful by-products and are not conducive to mass manufacturing. There is an urgent need to develop a simple methodology to synthesize vanadium oxide nanowires which is cost-effective and conducive to large-scale manufacturing. Here, we report for the first time a simple and inexpensive process for growth of VO NWs using a single zone quartz tube furnace without a vacuum system.

\section{Experimental}

\section{Synthesis}

The nanowires were grown using the thermal evaporation technique in a 2-inch quartz tube furnace. The donor material, $\mathrm{V}_{2} \mathrm{O}_{3}$ nanoparticle powder, was placed upstream of the silicon substrate, coated with a 100-nm-thick $\mathrm{Au}$ film, upon which the wire growth was desired. Figure 1a shows the layout of the experimental apparatus. The donor material was placed $60 \mathrm{~mm}$ from inlet, the substrate was placed $310 \mathrm{~mm}$ from inlet for growth at 1100 and $1075{ }^{\circ} \mathrm{C}$. It was moved to $302 \mathrm{~mm}$ for growth at $1000{ }^{\circ} \mathrm{C}$ to maintain substrate temperature. The furnace was taken through a heating cycle involving a heating ramp at $10{ }^{\circ} \mathrm{C}$ per minute, growth period ranging from 2 to $5 \mathrm{~h}$ and a cooling procedure which takes up to $2 \mathrm{~h}$, depending on the growth temperature. The constant volumetric flow rate for the carrier gas, argon, was $70 \mathrm{ml} / \mathrm{min}$. The authors have considered the effect of Ar flow rate on the growth of nanowires. The nanowires ceased to grow for Argon flow rates above $70 \mathrm{ml} / \mathrm{min}$ and below $40 \mathrm{ml} / \mathrm{min}$. Between the 40 and $70 \mathrm{ml} / \mathrm{min}$ range, the nanowire growth rate was found to increase with the growth rate. The optimal Argon flow rate was found to be $70 \mathrm{ml} / \mathrm{min}$ and hence used in these experiments.

The donor material was heated in an argon environment and the constituent atoms were carried downstream by the carrier gas to the much cooler substrate material. The substrate position was crucial since there was a temperature gradient from the center of the heat zone to the end of the quartz tube. The temperature profile, shown in Fig. 1b, was simulated using ANSYS and was used to determine the appropriate position for the substrates. It was found that the most abundant growth occurred at $150 \mathrm{~mm}$ from the center of the heat zone, in which the simulation correlates to approximately $300{ }^{\circ} \mathrm{C}$.

\section{Nanowire characterization}

The nanowire morphology was observed using a Zeiss Sigma VP scanning electron microscope (SEM) with an Oxford $50 \mathrm{~mm}$ SDD EDS at high vacuum. Since the substrate was initially coated with a 100-nm-thick layer of
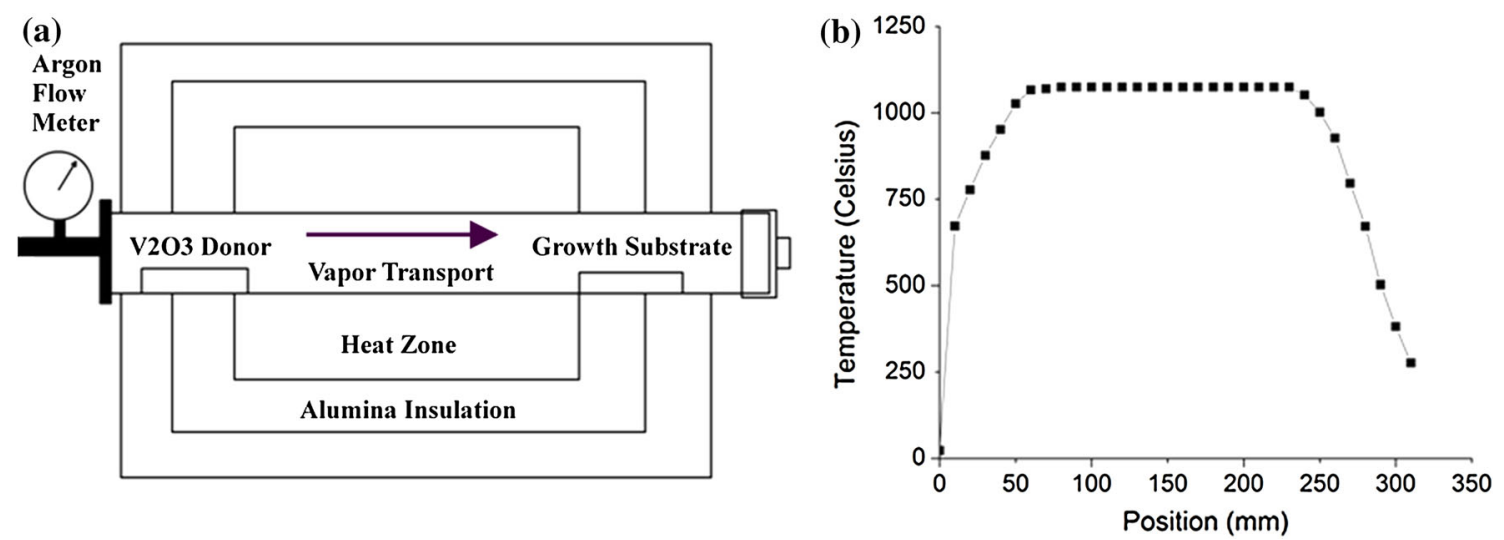

Fig. 1 a Schematic of the growth apparatus using an MTI single heat zone furnace with a 2-inch quartz tube. b Fluent simulated temperature profile within the quartz tube along the centerline 
gold there was no preparation required for the NWs prior to imaging. The substrates were placed in sample containers after each trial and checked for growth within 1 week of the trial. The NWs were imaged at low electron acceleration energy ( 2 and $5 \mathrm{keV}$ ) to reduce charging and to compensate for electron transparency of the NWs. The elemental composition of the NWs was obtained using the energy dispersive X-ray spectroscopy (EDS) technique. The energy data were then analyzed using Aztec 2.4 EDS software to determine the nanowire elemental stoichiometry. To obtain more accurate results, a lower than typical excitation energy was used to increase the ratio of signal in favor of the NWs rather than the substrate. The texture of the nanowires was analyzed using a Rigaku SmartLab X-ray Diffractometer equipped with a $\mathrm{Cu} \mathrm{K}_{\alpha}$ source. The sample was aligned in the instrument using the built-in laser alignment system. Further, a Fourier Transform Infrared spectrum was obtained using a Thermo Nicolet NEXUS 470 FTIR spectrometer. The spectrum was obtained for wavenumbers ranging from 600 to $4000 \mathrm{~cm}^{-1}$. A background spectrum was taken in air prior to obtaining the spectrum from the nanowire sample.

\section{Results and discussion}

Figure 2 shows the SEM image of the synthesized nanowires. While Fig. 2a represents the growth at $1100{ }^{\circ} \mathrm{C}$ for $3 \mathrm{~h}$, Fig. $2 \mathrm{~b}$ indicates growth after heating at $1000^{\circ} \mathrm{C}$ for $3 \mathrm{~h}$. The nanowires appear to have a pillar like structure giving it a 3-D form. A close inspection also reveals pointy tips. The nanowire surface appears to be smooth. The average width of the nanowires was found to be 113 and $65 \mathrm{~nm}$ for growth temperature of 1100 and $1000{ }^{\circ} \mathrm{C}$, respectively. The heating temperature was found to influence the nanowire width. The average length of the nanowires was found to be $0.7 \mu \mathrm{m}$ for a $3 \mathrm{~h}$ growth at $1100{ }^{\circ} \mathrm{C}$. The average length of the nanowires was not influenced by the heating temperature.

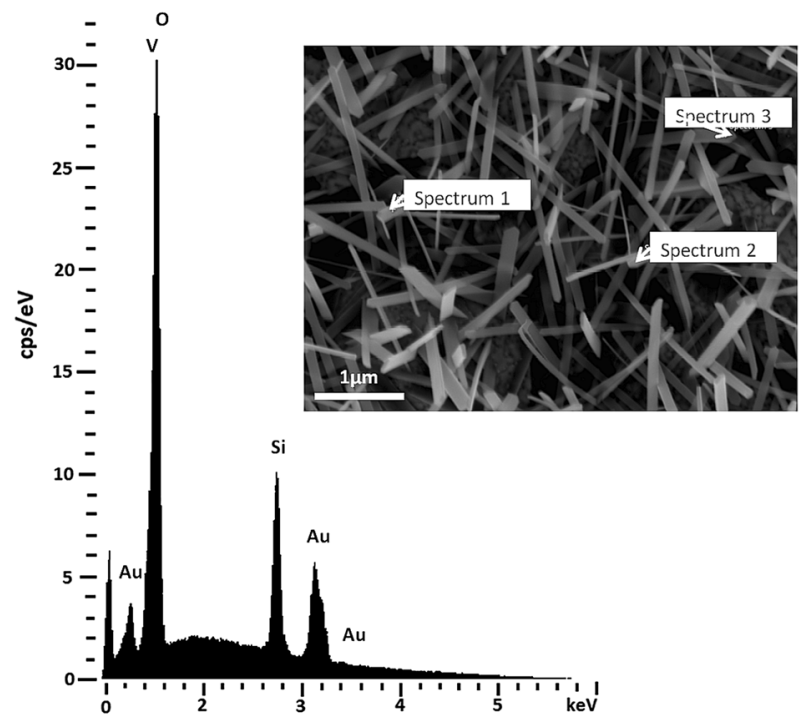

Fig. 3 EDS spectra of the nanowires grown at $1075{ }^{\circ} \mathrm{C}$ for $3 \mathrm{~h}$ using $5 \mathrm{keV}$ acceleration. Inset SEM micrograph shows the analyzed area

The orientation of the nanowires seems to be determined by the interaction between the catalyst and the nanowire in which the lowest energy configuration is preferred. The tips of the nanowires had an angular structure present on virtually all nanowires independent of orientation, size, and position on substrate, suggesting that this phenomenon is related to the crystal structure rather than environmental factors. In addition, the cross-sectional geometry is likely due to a difference in growth rate along specific crystal orientations.

The nanowire composition and stoichiometry was determined from EDS and XRD measurements. The EDS spectrum shown in Fig. 3 indicates the presence of V, O, $\mathrm{Si}$, and $\mathrm{Au}$. The SEM micrograph shown as an inset represents the nanowire location from where the spectrum was obtained. The energy spectra when analyzed using Aztec 2.4 EDS software gave an atomic percent composition of $40.45 \% \mathrm{O}, 42.01 \% \mathrm{~V}, 12.30 \mathrm{Si}$, and $5.24 \% \mathrm{Au}$. After background correction, the stoichiometry of nanowires was
Fig. 2 SEM micrograph of the nucleated nanowires after heating the substrate for $3 \mathrm{~h}$. a Growth at $1100{ }^{\circ} \mathrm{C}$ and b growth at $1000{ }^{\circ} \mathrm{C}$
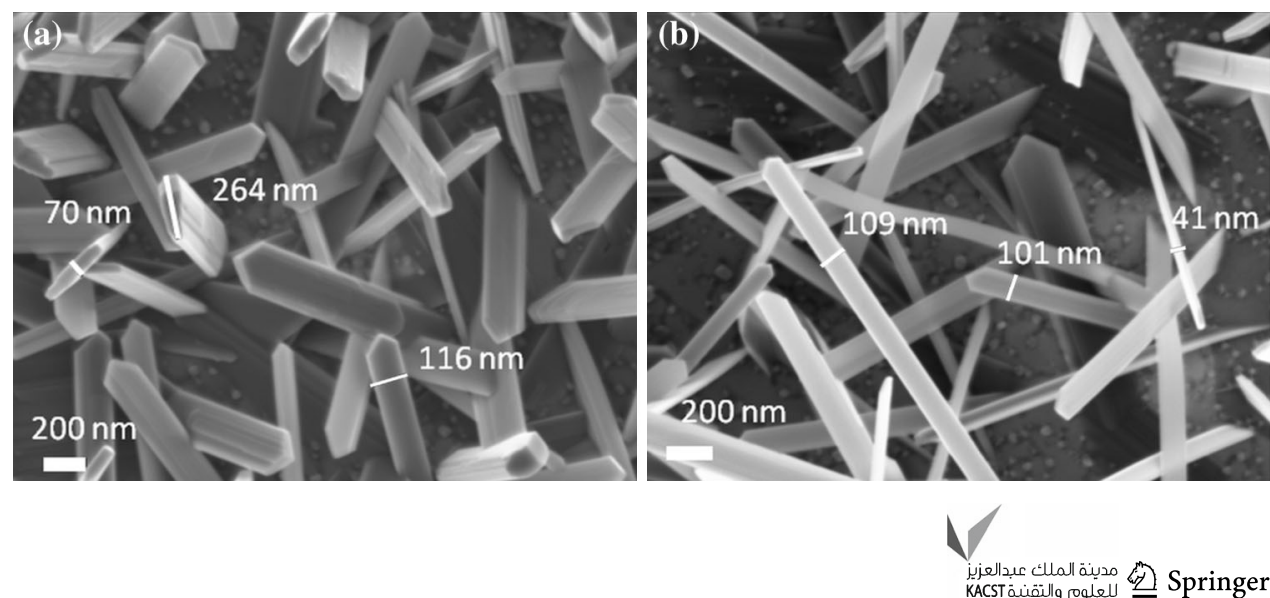


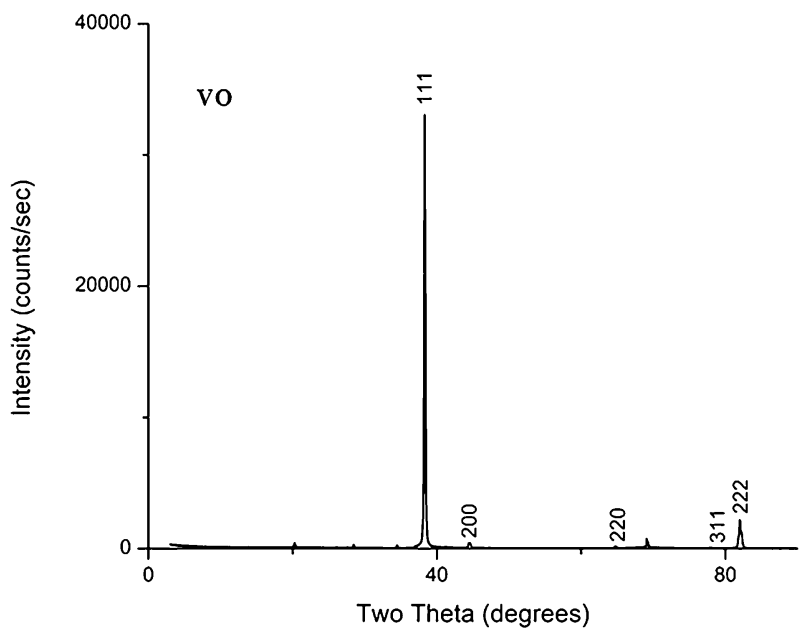

Fig. 4 XRD crystallographic spectra of nanowires grown at $1075{ }^{\circ} \mathrm{C}$ indicating polycrystalline texture of $\mathrm{VO}$

found to be VO. Such an observation was confirmed by the XRD results. Figure 4 shows a representative XRD pattern of the nanowire sample which indicates the crystalline nature of the nanowires. The slit size for incidence was chosen so that the majority of the spectrum is from the nanowires and not from the substrate. The XRD peaks can be indexed to VO (JCPDS 44-0252). Though the nanowire sample seems to be of polycrystalline nature, a dominance of (111) planes is observed. Figure 5 shows the FTIR spectrum in the transmittance mode. The peaks at 2361 and 2341 are attributed to the stretching and bending vibrations of short $\mathrm{V}=\mathrm{O}$ bonds, respectively. These analytical measurements indicate that the composition of the nanowires is that of $\mathrm{VO}$.
Next, the time dependence on the nanowire growth sample was studied. The Au-coated Si samples were heated at $1075{ }^{\circ} \mathrm{C}$ for four different heating times: $3 \mathrm{~h}, 2 \mathrm{~h}, 1 \mathrm{~h}$, and $1 / 2 \mathrm{~h}$. Figure 6 shows the SEM micrographs of the nanowire growth under different heating times. For comparison purposes, the SEM images were taken at the same magnification. A visual observation indicates a higher nanowire density for samples heated to $3 \mathrm{~h}$. In contrast, the average width of the nanowires appears to be independent of the growth time. However, for a quantitative comparison, the number density of nanowires was estimated. The density of the wires was estimated by counting the wires in $1 \mu \mathrm{m} \times 1 \mu \mathrm{m}$ regions in the SEM image and averaging them. Table 1 summarizes the results on the number density estimation as a function of heating time. There seems to be a fourfold increase in the number density of wires when the heating time was increased from 30 min to an hour. Upon increasing the heating time further up to $3 \mathrm{~h}$, the number density more than doubled. The drastic change in the number density of nanowires can be attributed to the nucleation of wires from newer gold catalyst islands. Table 1 gives a glimpse of the growth kinetics of the VO nanowires. The wires tend to evolve from the substrate around the $30 \mathrm{~min}$ mark and tend to saturate around the 3-h timescale.

After time dependence, the influence of heating temperature on nanowire growth was studied. The SEM micrographs in Fig. $7 \mathrm{a}-\mathrm{d}$ show the nanowire growth for $3 \mathrm{~h}$ at $1100,1075,1000$, and $900{ }^{\circ} \mathrm{C}$, respectively. The growth at $1100{ }^{\circ} \mathrm{C}$ produced nanowires with an average width of $113 \pm 53 \mathrm{~nm}$, growth at $1075{ }^{\circ} \mathrm{C}$ produced nanowires of $75 \pm 40 \mathrm{~nm}$ width, and the sample at
Fig. 5 FTIR spectrum of the nanowires grown at $1075^{\circ} \mathrm{C}$ for $3 \mathrm{~h}$

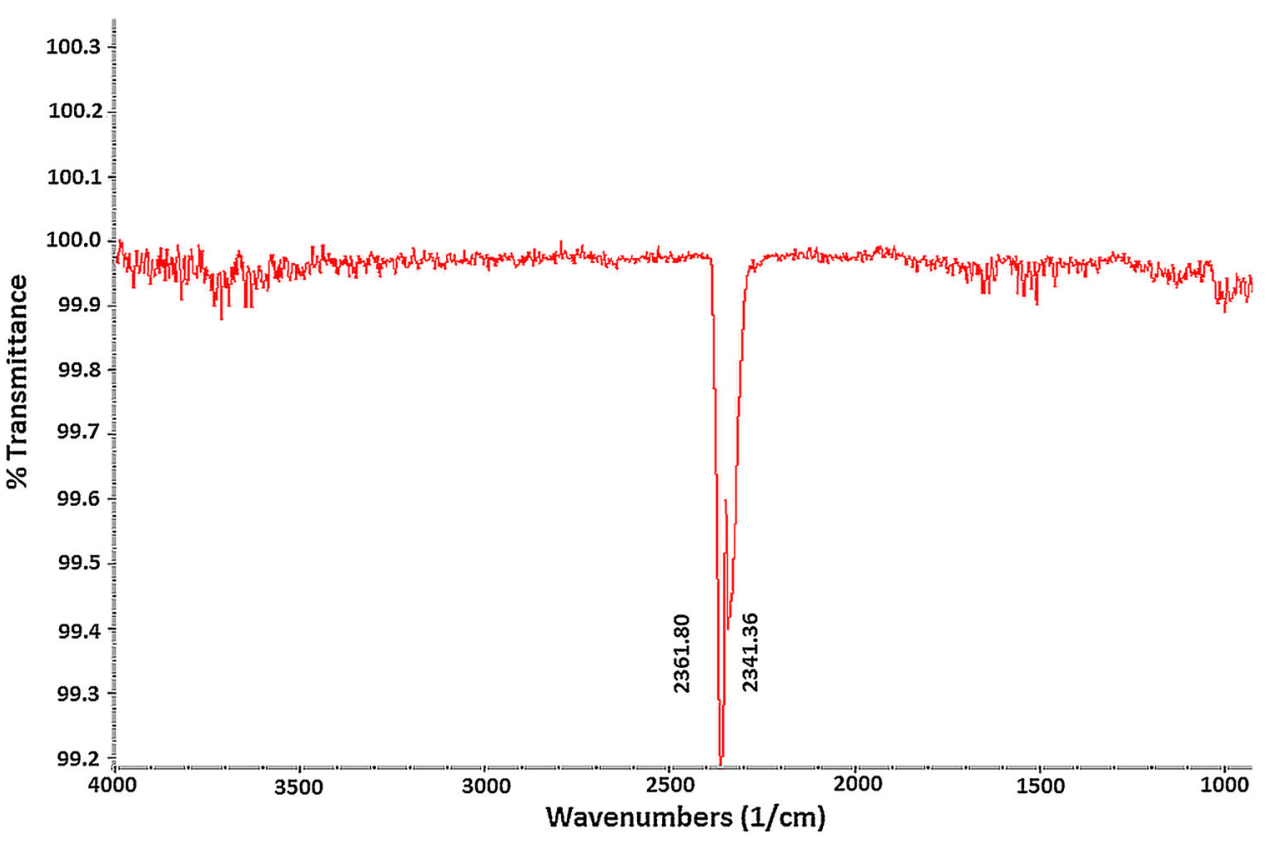


Fig. 6 SEM micrograph of VO nanowire growth at $1075{ }^{\circ} \mathrm{C}$ after a $3 \mathrm{~h}, \mathbf{b} 2 \mathrm{~h}, \mathbf{c} 1 \mathrm{~h}$, d $30 \mathrm{~min}$
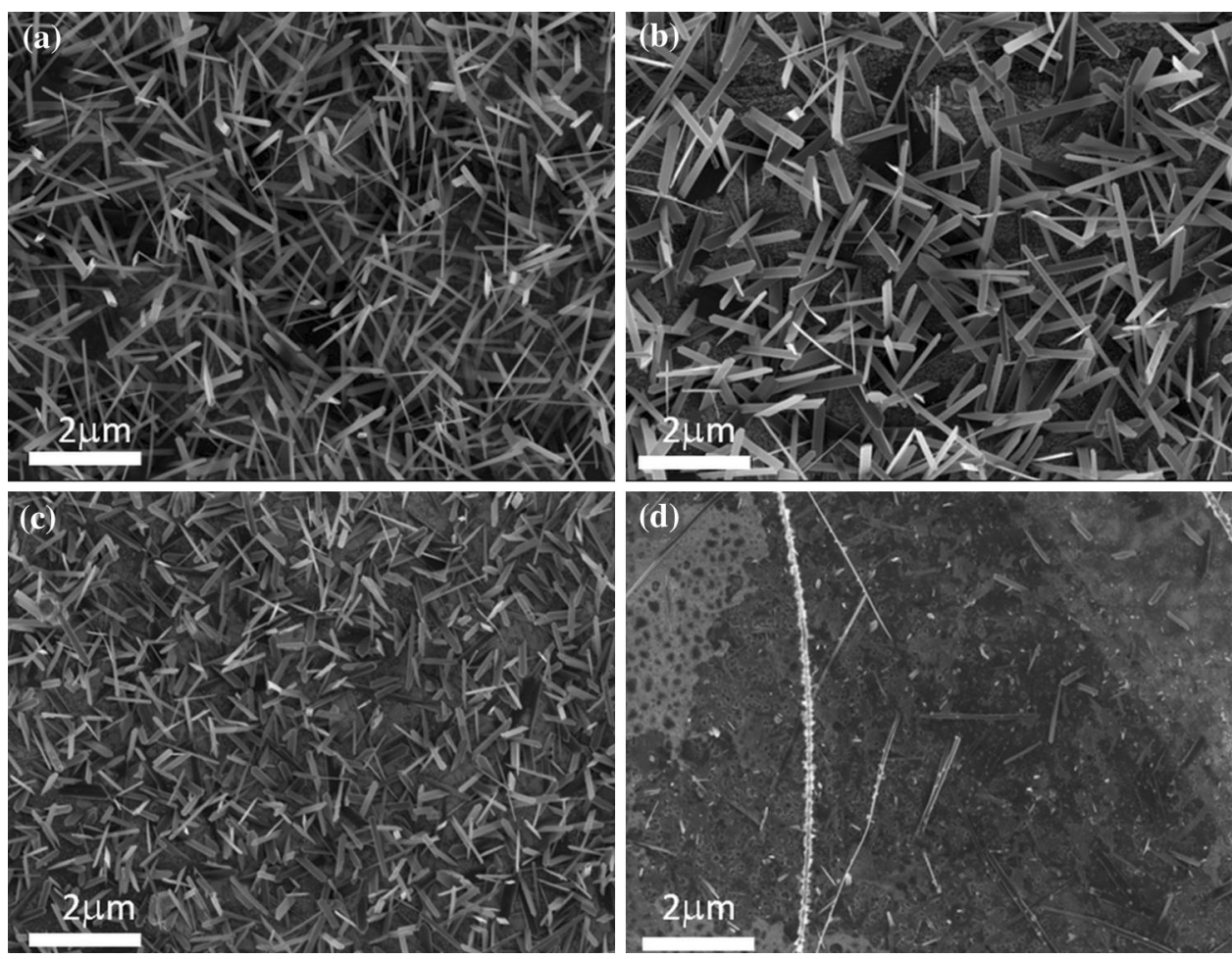

Table 1 Number density of the nanowires as a function of heating time

\begin{tabular}{ll}
\hline Heating time $(\mathrm{h})$ & Number density of nanowires $\left(\right.$ wires $\left./ \mathrm{cm}^{2}\right)$ \\
\hline 3 & $9 \times 10^{8}$ \\
2 & $7 \times 10^{8}$ \\
1 & $4 \times 10^{8}$ \\
0.5 & $1 \times 10^{8}$ \\
\hline
\end{tabular}

$1000{ }^{\circ} \mathrm{C}$ produced nanowires with width of $65 \pm 35 \mathrm{~nm}$. Absence of nanowire growth was observed at $900{ }^{\circ} \mathrm{C}$. A close inspection reveals Au nano-islands. It is noticed that the nanowire does not nucleate under three conditions: (a) there is no flow of Argon gas, (b) the heating temperature is below or equal to $900{ }^{\circ} \mathrm{C}$, and (c) the time at the growth temperature is less than $20 \mathrm{~min}$ and (d) Ar flow is less than $40 \mathrm{ml} / \mathrm{min}$ and greater than $70 \mathrm{ml} / \mathrm{min}$.

The structure of the nanowires and the absence of catalyst on the tip of the wires negate a complete dominance of the Vapor-Liquid-Solid (VLS) mechanism. Further, in our study, the nanowires were found to nucleate even on a quartz sample without a catalyst (SEM not shown). Hence, the requirement of a catalyst does not seem to be a necessity for VO nanowire growth. However, the catalyst seems to reduce the activation barrier for nanowire nucleation and increase the number density of the wires. Based on previous work by Kolasinski (2006) on catalytic growth of nanowires, the nanowire growth in this study can be explained by a root growth mechanism where the catalyst can be found at the root of the nanowires. Only a TEM inspection can reveal the exact growth mechanism of the nanowires. The authors, based on the available data, speculate dominant vapor-solid root growth mechanism.

\section{Conclusion}

A simple method to grow VO nanowires was reported. The nanowires were grown using an open tube furnace with argon as the carrier gas. Gold-coated silicon was used as the substrate. The composition and stoichiometry of the nanowires were confirmed through EDS, XRD, and FTIR studies. The average width of the nanowires was found to be 113 and $65 \mathrm{~nm}$ for growth temperature of 1100 and $1000{ }^{\circ} \mathrm{C}$, respectively. The heating time influenced the number density of the nanowires. There seems to be a fourfold increase in the number density of wires when the heating time was increased from $30 \mathrm{~min}$ to an hour. Further, an increase in the heating temperature was found to increase the width of the nanowires. The growth mechanism is speculated to be a root growth mechanism. Future work involves (a) TEM studies to identify the precise growth mechanism, (b) use of other metal catalyst to lower the growth temperature, and (c) study the electrical properties of the nanowires for possible applications in sensor, battery, and thermoelectric devices. 
Fig. 7 SEM micrographs of $\mathrm{VO}$ nanowire growth at $3 \mathrm{~h}$ for different heating temperature. a $1100{ }^{\circ} \mathrm{C}$, b $1075^{\circ} \mathrm{C}$, c $1000{ }^{\circ} \mathrm{C}$, and d $900{ }^{\circ} \mathrm{C}$
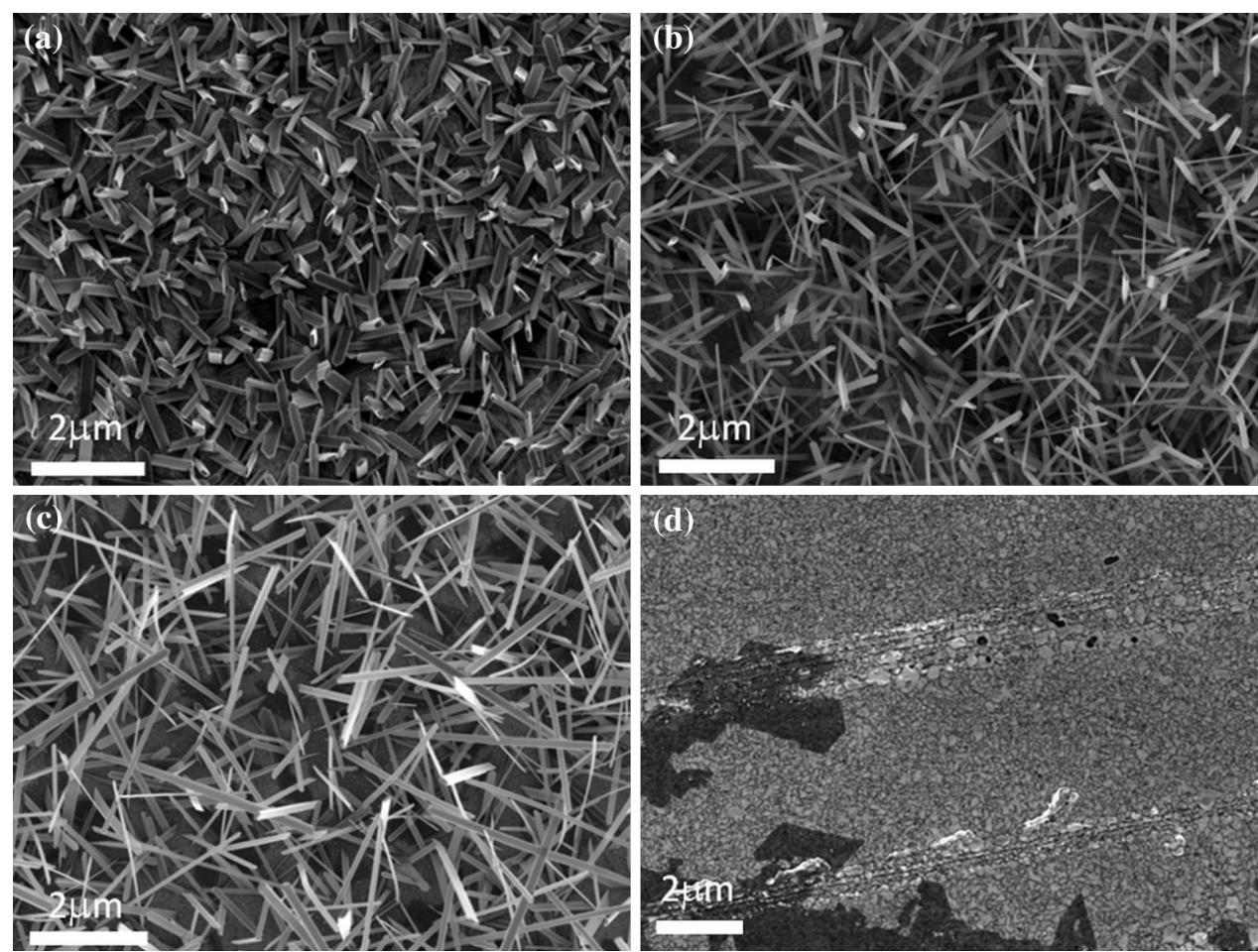

Acknowledgments The authors gratefully acknowledge the technicians at WSU Vancouver for assistance in conducting experiments and obtaining XRD data. P. K. Sekhar acknowledges the support of WSU Vancouver mini-grant for funding this work.

Open Access This article is distributed under the terms of the Creative Commons Attribution 4.0 International License (http:// creativecommons.org/licenses/by/4.0/), which permits unrestricted use, distribution, and reproduction in any medium, provided you give appropriate credit to the original author(s) and the source, provide a link to the Creative Commons license, and indicate if changes were made.

\section{References}

Cheng Y, Wong TL, Ho KM, Wang N (2009) The structure and growth mechanism of $\mathrm{VO} 2$ nanowires. J Cryst Growth 311:1571-1575

Cheng C, Liu K, Xiang B, Suh J, Wu J (2012) Ultra-long, freestanding, single-crystalline vanadium dioxide micro/nanowires grown by simple thermal evaporation. Appl Phys Lett 100 . doi:10.1063/1.3693381

Chou JY, Lensch-Falk JL, Hemesath ER, Lauhon LJ (2009) Vanadium oxide nanowire phase and orientation analyzed by Raman spectroscopy. J Appl Phys 105. doi:10.1063/1.3075763

Dhawan A, Sharma Y, Brickson L, Muth JF (2014) Incorporation of vanadium oxide films in optical fibers for temperature sensing and optical switching applications. Opt Mater Express 4:1128-1139

Fu H, Jiang X, Yang X, Yu A, Su D, Wang G (2012) Glycothermal synthesis of assembled vanadium oxide nanostructures for gas sensing. J Nanopart Res 14. doi:10.1007/s11051-012-0871-Z

Hong Y-X, Kuo W, Lin K-J (2011) Nonvolatile gating effects on radicals-containing vanadium oxide nanowires by gas molecule absorption and diffusion. Nanotechnology 22. doi:10.1088/09574484/22/11/115501

Horrocks GA, Singh S, Likely MF, Sambandamurthy G, Banerjee S (2014) Scalable hydrothermal synthesis of free-standing VO2 nanowires in the M1 phase. Appl Mater Interfaces 6:15726-15732

Kolasinski KW (2006) Catalytic growth of nanowires: vapor-liquidsolid, vapor-solid-solid, solution-liquid-solid and solid-liquidsolid growth. Curr Opin Solid State Mater Sci 10:182-191

Li S-Y, Namura K, Suzuki M, Niklasson GA, Granqvist CG (2013) Thermochromic VO2 nanorods made by sputter deposition: growth conditions and optical modeling. J Appl Phys 114. doi:10.1063/1.4813876

Liu J, Wang X, Peng Q, Li Y (2005) Vanadium pentoxide nanobelts: highly selective and stable ethanol sensor materials. Adv Mater 17:764-767

Mai L, Xu L, Han C, Xu X, Luo Y, Zhao S, Zhao Y (2010) Electrospun ultralong hierarchical vanadium oxide nanowires with high performance for lithium ion batteries. Nano Lett 10:4750-4755

Mai L, Xu X, Xu L, Han C, Luo Y (2011) Vanadium oxide nanowires for Li-ion batteries. J Mater Res 26:2175-2185

Perera SD, Liyanage AD, Nijem N, Ferraris JP, Chabal YJ, Balkus KJ (2013) Vanadium oxide nanowire-graphene binder free nanocomposite paper electrodes for supercapacitors: a facile green approach. J Power Sources 230:130-137

Wang Y, Cao G (2006) Synthesis and enhanced intercalation properties of nanostructured vanadium oxides. Chem Mater 18:2787-2804

Zhou X, Wu G, Gao G, Wang J, Yang H, Wu J, Shen J, Zhou B, Zhang Z (2012) Electrochemical performance improvement of vanadium oxide nanotubes as cathode materials for lithium ion batteries through ferric ion exchange technique. J Phys Chem 116:21685-21692 